Reprod. Nutr. Dévelop., 1987, 27 (1 B), 203-204.

\title{
Les variations saisonnières de la capacité d'ingestion des moutons en zone tropicale sèche
}

\author{
C. SALL, H. GUERIN, B. AHOKPE, D. FRIOT
}

avec la collaboration de A. NIANG

Laboratoire national de l'Elevage et de Recherches vétérinaires B.P. 2057, Dakar-Hann, Sénégal.

Summary. In order to measure the effect of the climate on voluntary food intake, ten adult rams were fed at maintenance level a diet of rice straw complemented with groundnut cake (9 to $15 \%$ of the DM) for two years. The total intake decreased from 59 to $51 \mathrm{~g}$ $\mathrm{DM} / \mathrm{W}^{0.75}$ from the cold dry season to the hot rainy season.

Le climat de la zone tropicale sèche est caractérisé par la succession d'un hivernage pluvieux et chaud et d'une saison sèche d'abord fraîche puis chaude. La température et l'hygrométrie agissent à la fois sur l'ingestibilité des fourrages et l'appétit des animaux (Michalet-Doreau et al., 1975 ; Friot, 1984). L'essai mis en place en novembre 1983 dans la région du Cap-Vert au Sénégal avait pour but d'étudier les variations saisonnières de la capacité d'ingestion de moutons adultes à l'entretien recevant une ration de composition constante au cours d'une période de deux années.

Matériel et méthodes. Dix béliers adultes (3-4 ans) entiers de race peul-peul d'un poids moyen de $46 \mathrm{~kg}$ (39 à 53) ont été répartis 2 par 2 dans des boxes de $10 \mathrm{~m}^{2}$ d'une bergerie fermée. Le régime correspondant aux besoins d'entretien était à base de paille de riz hachée en brins de 5 à $10 \mathrm{~cm}$, distribuée à volonté (10\% de refus), contenant $82 \%$ de matière organique (MO) et $4 \%$ de matières azotées (MAT). La digestibilité de la matière organique de la paille mesurée sur des moutons était de $56 \%$. La paille était complémentée par du tourteau d'arachide $(500 \mathrm{~g}$ de MAT/ $\mathrm{kg} \mathrm{MS}$ ) à raison de $200 \mathrm{~g}$ par paire de moutons et par jour, et de $300 \mathrm{~g}$ en cas de perte de poids des animaux. Les moutons disposaient d'eau à volonté et recevaient en outre une complémentation minérale et vitaminique. Les moutons ont été pesés chaque semaine. Les quantités ingérées ont été mesurées, pour chaque paire de moutons, par pesée quotidienne des quantités distribuées et refusées.

Résultats et discussions. Les consommations maximales, de l'ordre de $1050 \mathrm{~g}$ de MS $(91 \%$ paille - $9 \%$ tourteau) par mouton et par jour (soit $59 \mathrm{~g}$ $\mathrm{MS} / \mathrm{kg} \mathrm{P} 0,75 / \mathrm{j}$ ) ont été atteintes en saison sèche fraîche, de décembre à mars (fig. 1). L'élévation de la température à partir d'avril, conjuguée avec celle de I'hygrométrie, s'accompagne d'une diminution progressive de la consommation de paille en saison sèche chaude, qui se poursuit avec l'arrivée des pluies en juillet. La diminution de l'ingestion a entraîné une perte de poids modérée $(2 \mathrm{~kg})$ des moutons qui a motivé une augmentation de la distribution de tourteau du 15 août au 15 novembre.

Les consommations minimales ont été observées en août et septembre au milieu de la saison des pluies : $915 \mathrm{~g}$ de MS (85\% paille - $15 \%$ tourteau) par 
mouton et par jour, soit $51 \mathrm{~g}$ de $\mathrm{MS} / \mathrm{kg} \mathrm{P} 0,75 / \mathrm{j}$; le coefficient de variation entre paires de moutons a été alors supérieur à celui observé en saison sèche : $11 \%$ en moyenne au lieu de $6 \%$. La diminution de l'ingestion par rapport à la saison sèche fraîche a été de $20 \%$ pour la paille et de $17 \%$ pour la ration entière, compte tenu de l'apport supplémentaire de tourteau en saison des pluies. Ce dernier a permis de maintenir les moutons à un poids et à un niveau d'alimentation à peu près stables : la quantité de matière organique digestible ingérée est restée comprise entre 25 et $29 \mathrm{~g}$ de $\mathrm{MOD} / \mathrm{kg} \mathrm{P}^{0,75}$, ce qui correspond aux besoins d'entretien des ovins en zone tempérée.

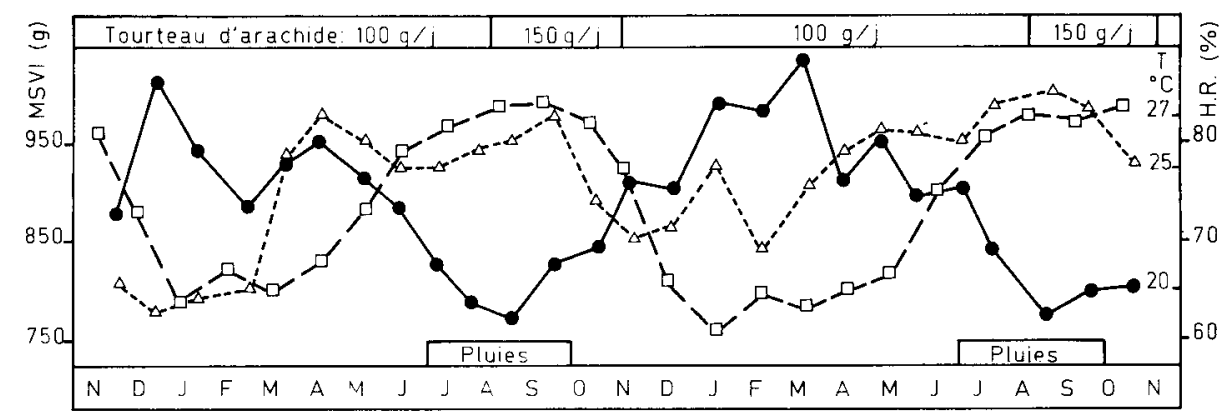

FIG. 1. - Variations mensuelles de la consommation de paille de riz (MSVI en g/mouton/jour: - ) par des moutons à l'entretien, de la temperature (T en ${ }^{\circ} \mathrm{C}: \square$ ) et de l'humidité relative (H.R. en $\%: \triangle l$ moyennes, d'après les relevés du service de la Météorologie Nationale effectués à Dakar.

Les moyennes hebdomadaires de consommation de paille (MSVI paille en g) durant les 102 semaines de l'essai sont reliées aux paramètres climatiques par l'équation :

MSVI paille $=1525-18,5 \mathrm{~T}-2,4$ H.R. $\pm 58 \quad \mathrm{r}=0,735 \mathrm{n}=102$

T. et H.R. étant les moyennes (des minima et des maxima) hebdomadaires des températures et des humidités relatives.

Berbigier (1983) a mis en évidence des effets comparables des variables climatiques sur l'ingestion de taurillons créoles en l'absence d'abris, mais beaucoup plus discrets dans le cas contraire. Cependant la comparaison entre les deux essais ne peut être que, limitée, car celui réalisé en Guadeloupe ne concernait que la saison sèche, alors qu'au Sénégal les plus grandes variations des quantités ingérées ont été enregistrées entre la saison sèche et la saison des pluies.

En conclusion, les variations saisonnières de la capacité d'ingestion des moutons à l'entretien en stabulation sont importantes en zone sahélienne. II faudra en tenir compte dans l'estimation de l'ingestibilité des fourrages et des rations disponibles dans ces régions.

Berbigier P., 1983. Ann. Zoot., 32, 93-108.

Friot D., 1984. No 35/Physio/LNERV.

Michalet-Doreau B., Xandé A., 1979. Ann. Zoot, 28, 381-392. 